The swift spread across Asia this year of the deadly H5N1 strain of avian influenza served as a grave warning of a possible flu pandemic like the one in 1918, which killed more than 20 million people.

The virus infected wild birds, cats, tigers, ducks and pigs and drove governments to cull more than 200 million domestic fowl, wreaking economic havoc in the region. It also claimed 32 human lives as of 17 November. H5N1 transmission between people appears to be rare thus far, but its presence in pigs-which also harbor human flu viruses-sparked fears that the virus could mutate into a strain against which humans have no immunity. Although last year's epidemic of severe acute respiratory syndrome boosted infectious disease surveillance, there are still significant gaps. Reports of H5N1 infection in pigs languished undiscovered in Chinese language journals for seven months (Nature 430, 955; 2004).

Meanwhile, the US was left 48 million doses short of its flu vaccine need when one of the country's two major suppliers was closed down as a result of lab contamination. The shortage highlighted problems in flu preparedness and vaccine production. The World Health Organization in November held a summit of health agencies and vaccine manufacturers to speed up vaccine development for pandemic flu strains. Meanwhile, the US National Institutes of Health announced a multicenter scheme to sequence thousands of strains of human and avian influenza viruses.

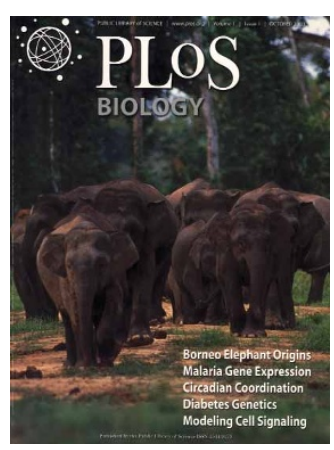

The debate on open access to scientific literature intensified this year, as governments and influential scientific organizations increasingly took sides on the movement's significance.

In Britain, an inquiry by the House of Commons Science and Technology Committee concluded in July that open access seems viable but requires further experimentation. The committee advised the government to require

UK-based authors to publish articles on their institutions' websites, but the government largely rejected the advice on 8 November. In August, 25 Nobel laureates signed a letter calling on the US government to provide public access to government-funded research. As a result, the US National Institutes of Health in September invited comments on a proposal to make the results of all federally funded research freely available shortly after publication. And in October, the German government gave $€ 6.1$ million to the Max Planck Society to develop an open-access system for publications from the society's institutes.

Meanwhile, 48 biomedical societies united to oppose open access. On 16 March, they launched a series of Principles for Free Access to Science, which backs open access but reserves the right of publishers to charge for several months after publication. Society editors argued that it would be impossible to generate income for other society activities if they only raised money through payments from authors.

\section{in 2004}

5 number of countries that this year

5 approved stem cell research (China, Japan, Singapore, France, Spain)

29 number of countries that now allow

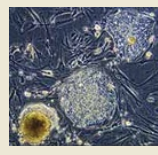
stem cell work

Number of human embryonic stem cell lines US President Bush authorized for research

Number of those grown on mouse 'feeder' cells and therefore unsuitable for medical use

30.5 Percent of obese adults in the US

Percent increase in the likelihood of

6 becoming obese per hour spent in a car each day

81 5 pounds of corn sweeteners

81.5 consumed per capita in the US each year

586 percent increase in corn sweetener consumption

$20 \begin{aligned} & \text { percent increase since } 1985 \text { in the price of a soft drink } \\ & \text { in the US }\end{aligned}$

118 percent increase since 1985 in the price of fresh

$1 \bigcirc$ federal subsidies, in billions of dollars, to the US

(Sources: CDC, Am J. Prev. Med. 27, 87-96; 2004, USAID, Oxfam)

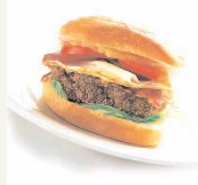

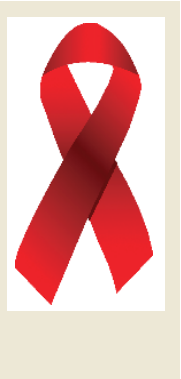

(Sources: MSF, World Bank)

Cost in dollars of a year's supply of a brand-name cocktail therapy for HIV/AIDS

11 Cost in dollars of a year's supply of the generic version

211 Average annual salary in dollars 3,440 in Botswana $2 \Omega$ Percent of Botswana's adult population afflicted with HIV/AIDS
2 Amount in billions of dollars that

33 pharmaceutical companies spent in 2003 on research and development

11 amount in billions of dollars they spent on marketing, not including 'medical education' of doctors

22 amount in billions of dollars from drug sales

20 Number of new drugs approved this year by the US Food and Drug Administration

8 Number of books published this year on the 'evils' of pharma

(Sources: PhRMA, Centerwatch) 


\section{News}

in 2004

32 number of years in a row with increasing enrollment of foreign students in US universities $204 \begin{aligned} & \text { Year in which that trend } \\ & \text { reversed }\end{aligned}$

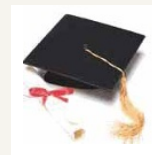
10 percent decrease this year in admission of foreign 1 students in life sciences at US universities

$100 \begin{aligned} & \text { number of researchers whose visa applications } \\ & \text { were flagged for review in } 2000\end{aligned}$ $1100 \begin{aligned} & \text { number whose visa applications were } \\ & \text { flagged for review in } 2002\end{aligned}$

(Sources: IIE, Council of Graduate Schools, GAO)

9 number, in millions, of high-risk Y people in the US who need flu shots $6 \bigcirc$ number, in millions, of doses $\bigcirc$ available.

12 number, in millions, of doses that

$1 \angle$ remained unused in 2002

20 Cost in dollars of the average flu shot

3,500

Cost in dollars of a year's supply of Viagra

27785 number of heart attacks between 19992,852003 attributed to Vioxx use

25 revenue in billions of dollars from Vioxx sales $\angle .5$ in 2003

28 amount in billions of dollars lost in shareholder value after Vioxx was pulled from the market

(Sources: FDA, Associated Press)

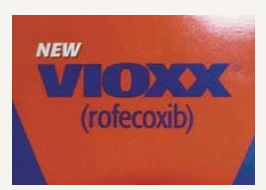

18 amount in millions of dollars Americans spent 48.6 out of their own pockets on prescription drugs $414 \begin{aligned} & \text { Amount in millions of dollars they spent on } \\ & \text { prescription drugs in Canada in } 2002\end{aligned}$ Amount in billions of dollars they 695 spent on prescription drugs in Canada in 2003

(Sources: CMMS, IMSHealth)

6 projected cost in billions of dollars of California's stem cell initiative revenue lost in billions of dollars from

4 Governor Schwarzenegger's rescindment of vehicle license fees

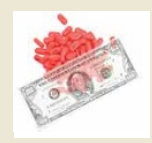

$1 \bigcirc$ amount in billions of dollars estimated to be California's deficit
Reproductive biology took a few promising, and rather bizarre, turns this year. Succeeding where many others had failed, Korean scientists revealed in February that they had created the first cloned human embryo. In March, another team announced the birth of a monkey from frozen ovarian tissue transplanted under the abdomen. Just months later, a cancer survivor gave birth to the first baby girl born from an ovarian transplant (Lancet 364, 1405-1410; 2004). The ovary had been frozen before the woman had received chemotherapy for an advanced case of Hodgkin lymphoma; the baby was conceived naturally (Nature 428, 137-138; 2004).

Researchers have also successfully transplanted ovaries into the arm.

In many ways, this was the year for female fertility. The popular media particularly loved the story of fatherless mice (Nature, 428, 860-864; 2004), born through parthenogenesis, a process more familiar to other species such as lizards, in which the embryo develops directly from an egg. A separate study also overturned the dogma that female mammals are born with all the eggs they will ever have. Mice were found to keep pumping out new eggs from stem cells well after birth (Nature 428, 145-150; 2004).

Compounded by controversy over pharmaceutical company practices, regulating and registering clinical trials this year took on an added urgency. On 1 May, the European Union launched its clinical trials directive to normalize and improve trials. The new regulations are intended to establish the legal obligations of trial sponsors and ensure greater patient protection. But some academic researchers have protested the directive since its announcement in 2001 , saying it will be difficult for them to meet the regulatory requirements and cost. In March, the UK unveiled the National Clinical Research Network to centralize funding and regulation of clinical trials. And in April, the World Health Organization, in conjunction with Current Controlled Trials, part of an independent publishing group, announced an online registry to improve tracking and comparison of randomized trials worldwide. The issue intensified when, responding to concerns about the selective reporting of trial data, the editors of 11 leading medical journals announced in September that registering trials in a free, searchable public database would be a prerequisite for considering manuscripts for publication in their journals. In October, the US Senate and Congress introduced legislation seeking mandatory registration of clinical trials.

RNA interference-which uses short fragments of RNA to block the production of specific proteins - this year cleared several hurdles in its path to becoming an approved therapy for human diseases.

Two companies-Acuity Pharmaceuticals in August and Sirna Therapeutics in September-filed applications with the US Food and Drug Administration to begin testing the technique's ability to treat age-related macular degeneration by interfering with the growth of new blood vessels. This year also saw several reports documenting the method's effectiveness in silencing gene expression in animal models of disease. One notable report showed that, delivered intravenously, short interfering RNAs targeted to an apolipoprotein can lower serum cholesterol in mice (Nature 432, 173; 2004).

Whether the technique can treat diseases in people remains to be seen. Researchers are still investigating whether the RNA fragments can be delivered in sufficient quantities to relevant tissues, how specific they are for their intended targets and what sorts of toxicities they might produce. 


\section{Newsmakers}

\section{in 2004}

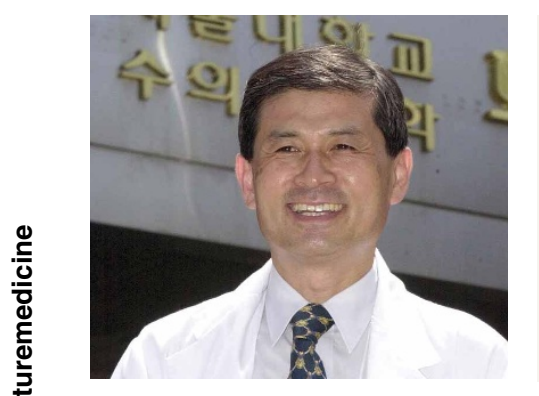

In a year full of stem-cell firsts, two researchers stood out above their peers. Harvard University researcher Doug Melton $(R)$ announced in March that he had created 17 new stem cell lines with private funding. Melton has been pegged to codirect the new Harvard Stem Cell Institute, a privately funded venture banding together nearly 100 researchers. Woo Suk Hwang $(L)$ put South Korean science on the map by creating stem cells from a cloned human embryo-but his work is dogged by questions (Nature 429, 3; 2004) over whether female scientists in the lab provided some of the eggs for the experiment.
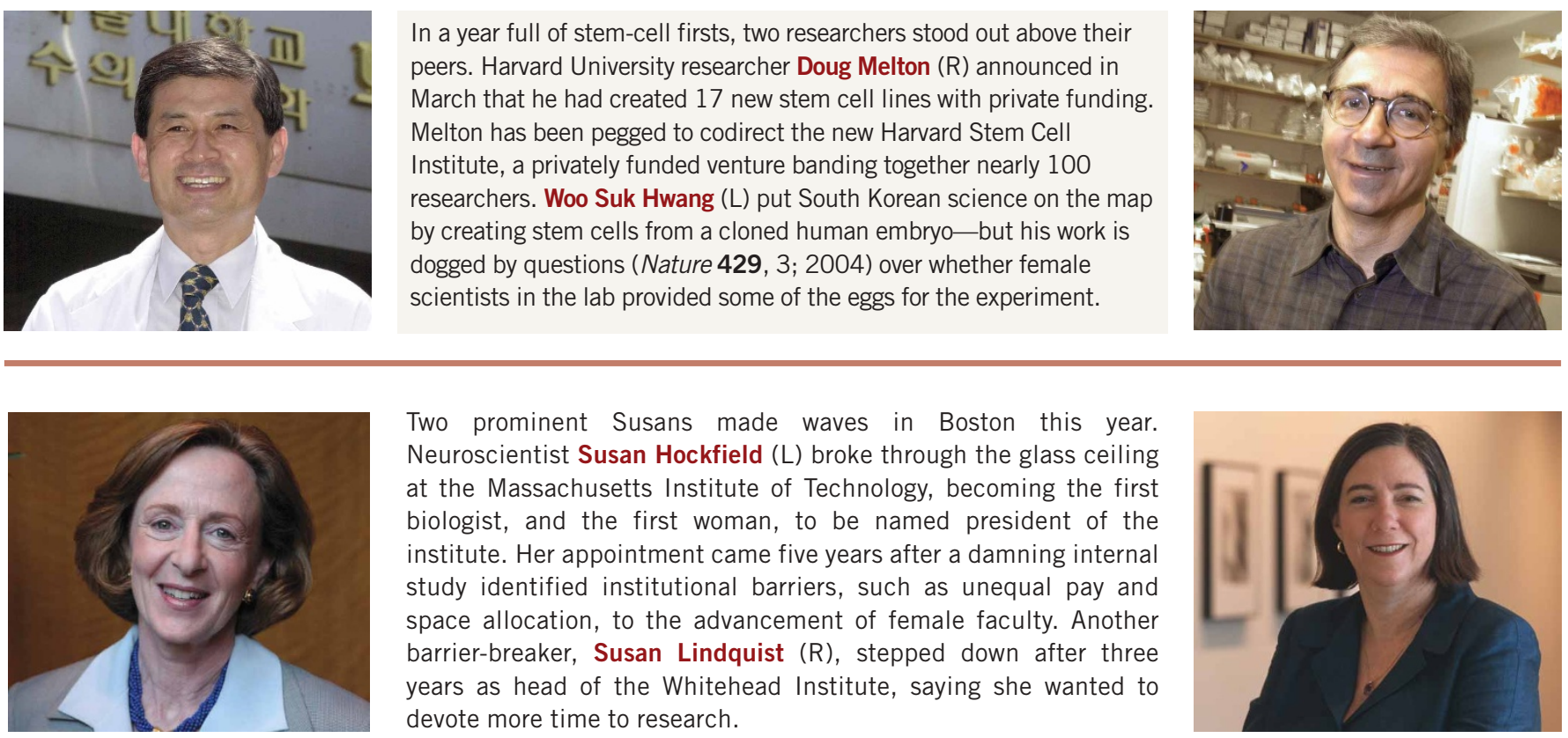

Two prominent Susans made waves in Boston this year. Neuroscientist Susan Hockfield (L) broke through the glass ceiling at the Massachusetts Institute of Technology, becoming the first biologist, and the first woman, to be named president of the institute. Her appointment came five years after a damning internal study identified institutional barriers, such as unequal pay and space allocation, to the advancement of female faculty. Another barrier-breaker, Susan Lindquist (R), stepped down after three years as head of the Whitehead Institute, saying she wanted to devote more time to research.

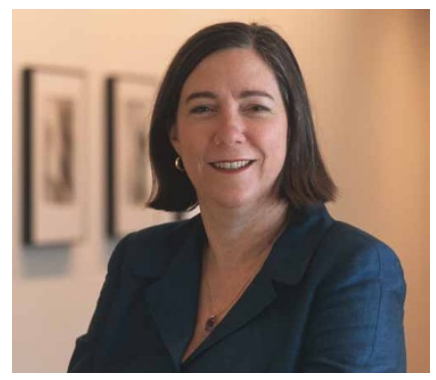

Christopher Reeve, who tirelessly championed the cause of stem cell research, died of heart failure on 10 October. He was 52. Confined to a wheelchair by his paralysis after a riding accident in 1995, the charismatic Man of Steel drew on his star power to boost the profile of research on stem cell therapies and spinal injury. Although Reeve died nearly a month before the US presidential election, his iconic status - and the foundation he created — continue to support the search for a cure.
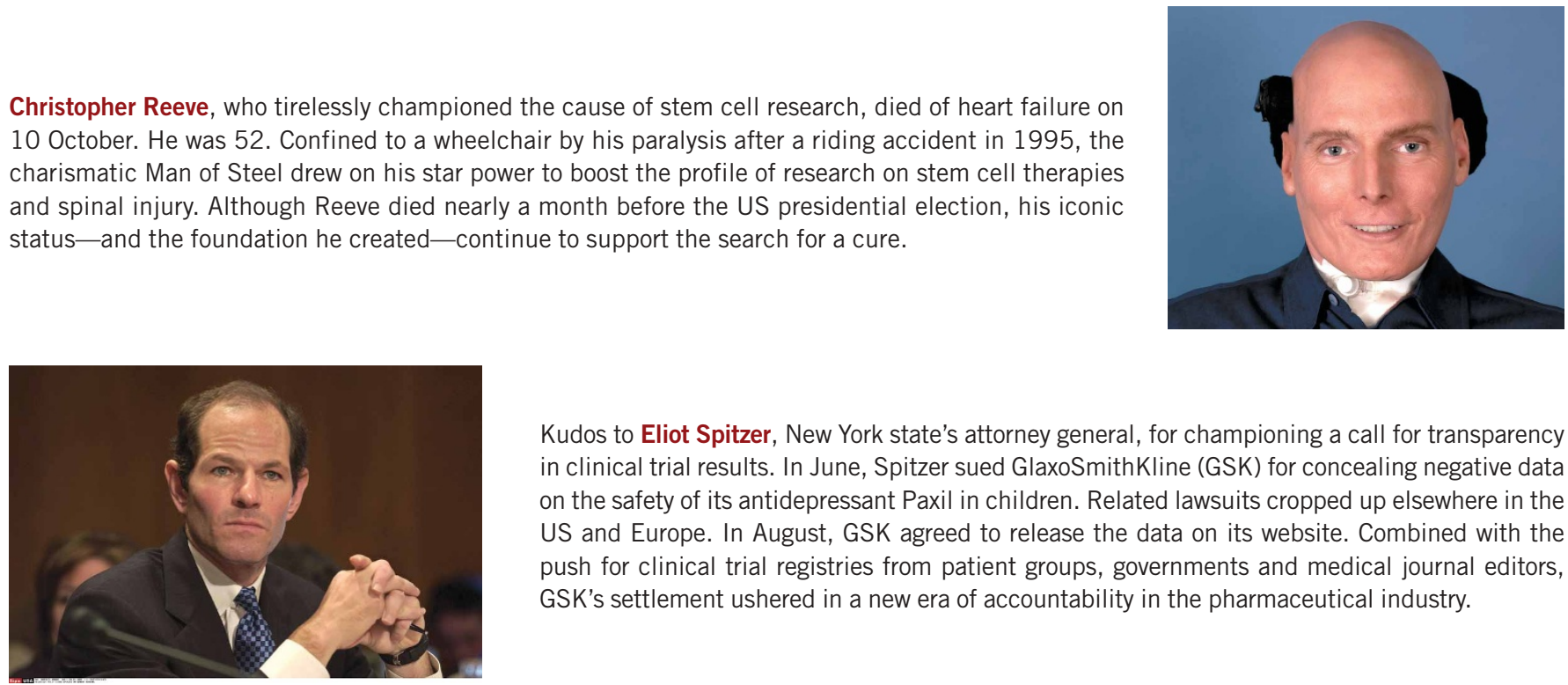

Kudos to Eliot Spitzer, New York state's attorney general, for championing a call for transparency in clinical trial results. In June, Spitzer sued GlaxoSmithKline (GSK) for concealing negative data on the safety of its antidepressant Paxil in children. Related lawsuits cropped up elsewhere in the US and Europe. In August, GSK agreed to release the data on its website. Combined with the push for clinical trial registries from patient groups, governments and medical journal editors, GSK's settlement ushered in a new era of accountability in the pharmaceutical industry.

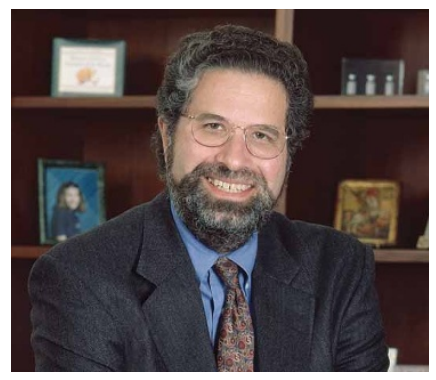

The small field of HIV vaccine research saw some reshuffling this year when two of its leaders switched places. After more than 20 years with the pharmaceutical giant Merck, Emilio Emini $(L)$ in January left to spearhead vaccine development at the New York-based nonprofit International AIDS Vaccine Initiative. Merck researcher John Shiver succeeded Emini as vice president of the company's vaccine division. Later in the year, Merck lured Mark Feinberg (R) away from Emory University to join its vaccine division as vice president of policy, public health and medical affairs.

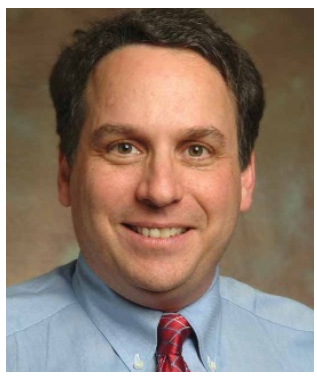




\section{Highs and lows}

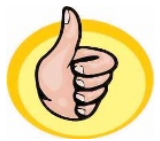

The UK government, for passing legislation protecting researchers from harassment by animal rights activists, and for doubling funds for developing alternatives to animal research.

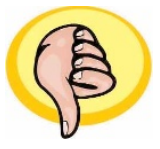

Cambridge University, for scrapping construction on a primate research facility, in response to pressure from animal rights groups.

(Nature 429, 334, 2004, Nat. Med. 10, 215; 2004)

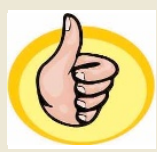

The Institute of Electric and Electronics Engineers, for challenging a US policy that forbade peer review, editing and publishing of scientific manuscripts from countries under US trade embargoes.

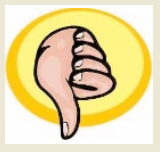

The US Department of Commerce, for proposing a system that would require scientists from countries such as China and India to obtain special licenses before they can work in US laboratories.

(Nature 427, 663, 2004, Nature 431, 615; 2004)

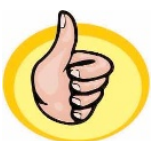

China, for driving a twenty-fold spike in its scientific publication rate over the past 22 years, and for responding swiftly and openly to the return of severe acute respiratory syndrome.

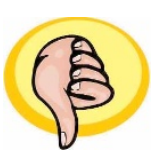

China, for laboratory practices that led to cases of severe acute respiratory syndrome, and for letting crucial avian flu data languish for months in untranslated journals.

(Nature 431, 116; 2004, Nature 430, 955; 2004)

The US National Institutes of Health director Elias Zerhouni, for defending nearly 200 grants to study sexual behavior that were flagged as unnecessary by the Traditional Values Coalition.

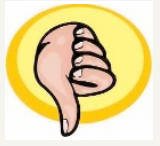

The US National Institutes of Health, for funneling \$2.3 million over the last four years into research on the power of prayer in medicine.

(Nature 427, 278; 2004, The New York Times)

Scientists in France, England, Spain and Italy, for taking to the streets to protest drastic funding cuts and job restructuring.

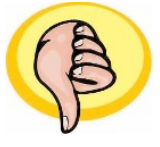

France, for reversing the policies by reinstating the cut jobs and increasing research funds.

(Nat. Med. 10, 319; 2004)

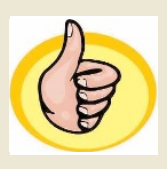

The UK, Spain, Singapore and others for backing stem cell initiatives, Harvard University for creating a stem cell center, and voters in California for resoundingly endorsing their stem cell inititiative.

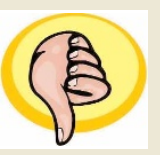

The Bush administration, for restricting federal funds to human embryonic stem cell lines that are increasingly proving unreliable, and for sacking stem cell supporters Elizabeth Blackburn and William May from the president's bioethics panel.

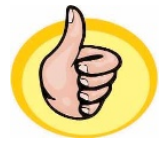

The US Food and Drug Administration, for banning, in April, sales of ephedra, based on evidence that the weight-loss supplement increases the risk of heart attack and stroke.

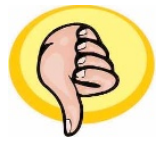

The US Food and Drug Administration, for dragging its feet over safety concerns about antidepressant use in adolescents and about Merck's anti-arthritis drug, Vioxx.
Scotland, Montenegro, Hong Kong, regions of Australia, the US and several others for prohibiting smoking in public spaces.
Philip Morris, for suppressing data showing passive smoke to be highly toxic compared with smoke inhaled directly from a cigarette. 


\section{Notable advances}

The influenza virus that killed more than 20 million people during the 1918 epidemic may be long gone, but interest in it lives on. This year, crystal structures of the receptor-binding protein from the 1918 virus - the viral hemagglutininrevealed that the virus shares features with

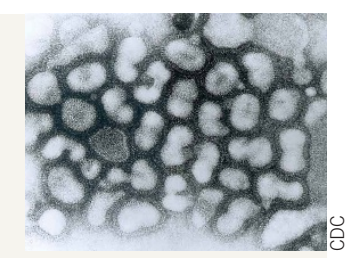
present-day avian influenza viruses. The gene that encodes hemagglutinin probably contributed to the extreme virulence of the 1918 strain: expressing the protein in an otherwise mild virus transforms the virus into a lethal strain.

Science 303, 1838-1842 and 1866-1870; 2004, Nature 431, 703-707; 2004.

How insulin-producing cells are generated in the adult pancreas has been a topic of considerable debate. Countering many previous studies implicating adult stem cells in this process, a new study used genetic marking techniques to show that-in mice, at leastit is preexisting beta cells that lead to insulin-producing cells. The results might lead to new approaches for transplanting the cells into diabetic individuals.

Nature 429, 41-46; 2004.

Two independent teams showed this year that patients who respond to the lung cancer drug Iressa (gefitinib) carry certain mutations in the epidermal growth factor receptor (EFGR). The US Food and Drug Administration in 2003 approved Iressa, an inhibitor of the EGFR kinase, despite poor evidence of benefit and a lack of correlation with EFGR expression. The new results underscore the need to identify patients who are most likely to respond to a drug.

Science 304, 1497-1500; 2004; N. Engl. J. Med. 350, 2129-2139; 2004.

To generate a T-cell response that can target and destroy specific cells-such as tumor cells-specialized antigen-presenting cells must first take up the antigen and 'crosspresent' fragments to $\mathrm{CD}^{+} \mathrm{T}$ cells. A trio of papers published this year indicated that the antigen-presenting cells must engulf whole proteins-not peptides-to effectively present the fragments. The studies are likely to advance the development of more effective vaccines.

Science 304, 1314-1317 and 1318-1321; 2004, Proc. Natl. Acad. Sci. USA 101, 3035-3040; 2004

A series of papers this year revealed a new way that cells sometimes fend off attacks from viruses. Investigating why rhesus monkey cells are resistant to HIV infection, one team discovered that a protein called Trim5alpha recognizes HIV's coat and blocks viral replication. Hot on the heels of this finding, several other groups reported that this antiviral system is used by many species,

including humans, to block the replication of several different viruses.

Nature 427, 848-853; 2004, Proc. Natl. Acad. Sci. USA 101, 10774-10779, 10780-10785 and 10786-10791; 2004.

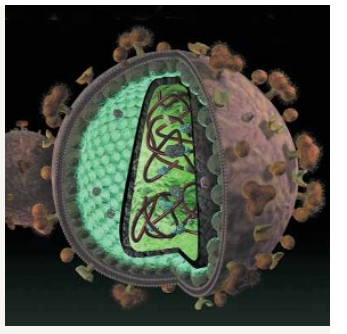

\section{in 2004}

Statins continue to be the mainstay for lowering cholesterol levels, but studies this year boosted alternative approaches. A small clinical study showed that an inhibitor of the cholesteryl ester transfer protein can raise HDL cholesterol levels and lower LDL cholesterol levels, both of which are thought to protect against atherosclerosis and cardiovascular disease. A second study identified the transporter responsible for absorption of dietary cholesterol, a finding that might lead to new therapies.

N. Engl. J. Med. 350, 1505-1515; 2004; Science 303, 1201-1204; 2004

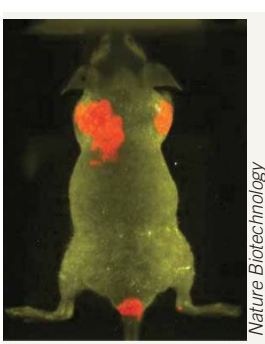

Tumors came alive in full molecular detail this year when researchers used advances in in vivo imaging to track them in real time. One team used positron emission tomography to light up the Her2 oncoprotein and tracked its response to a drug in mice. Another harnessed quantum dots, an emerging technology, to visualize prostate-specific cell-surface antigen in mice. The approaches could someday help identify patients that are most likely to respond to certain drugs, such as Iressa.

Nat. Biotech. 22, 701-706; 2004, Nat. Biotech. 22, 969-976; 2004

The immune system tailors its response to different types of pathogens-but how it does so has been a puzzle. Two papers this year showed that the Notch protein, which regulates development, also mediates dendritic cell signaling to $\mathrm{T}$ cells and directs $\mathrm{T}$-cell response to pathogens. Unraveling T-cell differentiation might benefit therapeutic approaches.

Cell 117, 515-526; 2004; Immunity 20, 611-622; 2004.

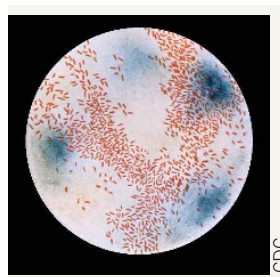

Cuban chemists this year cooked up a synthetic vaccine against Haemophilus influenzae, a bacterium that kills about 600,000 children worldwide each year. The sugar-based vaccine performed as well in clinical trials as the conventional vaccine made from the whole organism. The new recipe could help develop synthetic vaccines for diseases ranging from staphylococcus infections to malaria.

Science 305, 522-524; 2004

Commensal bacteria in the gut coexist peacefully with their host and may even confer health benefits. Two papers this year advanced our understanding of this symbiotic relationship. Dendritic cells keep the commensals from breaching the gut's mucosal wall by mounting an immunoglobulin A-mediated response. The bacteria also appear to stimulate Toll-like receptors in the gut epithelium to promote cell survival and repair during inflammation. The observations define new targets to treat inflammatory bowel disease.

Science 303, 1662-1665; 2004; Cell 188, 229-241; 2004 